\title{
Immune tolerance improves the efficacy of enzyme replacement therapy in canine mucopolysaccharidosis I
}

\author{
Patricia Dickson, ${ }^{1}$ Maryn Peinovich, ${ }^{1}$ Michael McEntee, ${ }^{2}$ Thomas Lester, ${ }^{3}$ Steven Le, ${ }^{1}$ \\ Aimee Krieger, ${ }^{1}$ Hayden Manuel, ${ }^{1}$ Catherine Jabagat, ${ }^{1}$ Merry Passage, ${ }^{1}$ and Emil D. Kakkis ${ }^{3}$ \\ 1Division of Medical Genetics, Los Angeles Biomedical Research Institute at Harbor-UCLA Medical Center, \\ Torrance, California, USA. ${ }^{2}$ Department of Pathobiology, College of Veterinary Medicine, University of Tennessee, \\ Knoxville, Tennessee, USA. ${ }^{3}$ BioMarin Pharmaceutical Inc., Novato, California, USA.
}

\begin{abstract}
Mucopolysaccharidoses (MPSs) are lysosomal storage diseases caused by a deficit in the enzymes needed for glycosaminoglycan (GAG) degradation. Enzyme replacement therapy with recombinant human $\alpha$-L-iduronidase successfully reduces lysosomal storage in canines and humans with iduronidase-deficient MPS I, but therapy usually also induces antibodies specific for the recombinant enzyme that could reduce its efficacy. To understand the potential impact of $\alpha$-L-iduronidase-specific antibodies, we studied whether inducing antigen-specific immune tolerance to iduronidase could improve the effectiveness of recombinant iduronidase treatment in canines. A total of 24 canines with MPS I were either tolerized to iduronidase or left nontolerant. All canines received i.v. recombinant iduronidase at the FDA-approved human dose or a higher dose for 9-44 weeks. Nontolerized canines developed iduronidase-specific antibodies that proportionally reduced in vitro iduronidase uptake. Immune-tolerized canines achieved increased tissue enzyme levels at either dose in most nonreticular tissues and a greater reduction in tissue GAG levels, lysosomal pathology, and urinary GAG excretion. Tolerized MPS I dogs treated with the higher dose received some further benefit in the reduction of GAGs in tissues, urine, and the heart valve. Therefore, immune tolerance to iduronidase improved the efficacy of enzyme replacement therapy with recombinant iduronidase in canine MPS I and could potentially improve outcomes in patients with MPS I and other lysosomal storage diseases.
\end{abstract}

\section{Introduction}

Lysosomal storage diseases are inherited diseases in which the deficiency of a catabolic lysosomal enzyme allows the accumulation of substrate within lysosomes, causing a diverse array of clinical syndromes. Mucopolysaccharidoses (MPSs) are a group of lysosomal storage diseases caused by the deficiency of an enzyme needed for the stepwise degradation of glycosaminoglycans (GAGs) that results in the soft tissue and connective tissue accumulation of GAG, resulting in progressive, multisystem disease and premature death. A treatment concept for these disorders arose in part from the discovery in 1968 that cocultured cells with different types of MPS could cross-correct each other's enzyme deficit via receptormediated uptake (1). This early work among many other critical contributions enabled the development of enzyme replacement therapy (ERT) for many lysosomal storage diseases.

ERT via i.v. administration of recombinant forms of the missing enzymes is currently available for many lysosomal storage diseases, including Gaucher disease, Fabry disease, Pompe disease, MPS I, MPS II, and MPS VI (2-7). Although some changes are irreversible, ERT has helped thousands of patients by reducing lysosomal storage and treating many systemic manifestations of their disease. However, certain tissues have been more resistant to

Nonstandard abbreviations used: ERT, enzyme replacement therapy; GAG, glycosaminoglycan; MPS, mucopolysaccharidosis; rhIDU, recombinant human $\alpha$-L-iduronidase.

Conflict of interest: E. Kakkis and T. Lester have ownership and income from BioMarin Pharmaceutical Inc., the manufacturer of Aldurazyme (laronidase); research support was provided by BioMarin Pharmaceutical Inc.

Citation for this article: J. Clin. Invest. 118:2868-2876 (2008). doi:10.1172/JCI34676 effective treatment, such as the renal tubules, cartilage, and heart valves (8). Further evaluation is required to understand the limitations of ERT in treating lysosomal storage diseases and to define approaches for improving ERT.

One possible limitation of ERT is the induction of anti-enzyme antibodies and the effect of these antibodies on enzyme distribution or action. ERT commonly produces an immune response to the therapeutic enzyme, with reported rates of antibody formation in treated patients ranging from $13 \%$ for Gaucher disease to $97 \%$ and $100 \%$ for MPS VI and Pompe disease, respectively $(4,7,9)$. Despite the presence of antibodies, in many cases a direct and proportional effect of the antibodies on efficacy has not been discernible, perhaps due to the complexity and heterogeneity of disease in patients. Antibody levels have not been precisely predictive of hypersensitivity or other adverse reactions to therapy, although the presence of antibodies is likely one required factor in infusion-associated adverse events.

An immune response is observed in most MPS patients during ERT. In MPS I, anti-iduronidase IgG antibodies are present in $91 \%$ of patients receiving ERT with recombinant human $\alpha$-L-iduronidase (rhIDU; Aldurazyme, laronidase), though titers may wane with time in some patients $(10,11)$. Even in the presence of antibodies, rhIDU ERT continues to be an effective treatment for MPS I patients, as shown in the clinical studies. However, recent evidence provided by Wraith and colleagues shows that during ERT, urinary GAG excretion is higher in patients with very high antibody titers to rhIDU, suggesting some reduction in the efficacy of rhIDU in decreasing urinary GAG excretion among patients with high titers (12). A similar observation has been made in a few patients treated 
Table 1

Experimental canine subjects

$\begin{array}{lccc}\begin{array}{l}\text { Canine } \\ \text { ID }\end{array} & \begin{array}{c}\text { Age at study } \\ \text { end }(\mathrm{mo})\end{array} & \begin{array}{c}\text { i.v. rhIDU } \\ \text { duration (wk) }\end{array} & \begin{array}{c}\text { Ab titer } \\ \text { (OD units/ } / \mathrm{l})\end{array}\end{array}$

Nontolerant, $0.58 \mathrm{mg} / \mathrm{kg} /$ wk dosage

$\begin{array}{llcc}\mathrm{Xb}^{A} & 31 & 27 & 28.4 \\ \mathrm{Xy}^{\mathrm{A}} & 31 & 27 & 38.9 \\ \mathrm{Ub}^{\mathrm{A}} & 35 & 26 & 61.4 \\ \mathrm{Et}^{\mathrm{A}} & 13 & 26 & 70.4 \\ \mathrm{Ni}^{\mathrm{A}} & 40 & 25 & 83.8 \\ \mathrm{U} \mathrm{I}^{\mathrm{A}} & 35 & 26 & 113 \\ \mathrm{Ye}^{\mathrm{A}} & 19 & 9 & 377 \\ \mathrm{Um}^{\mathrm{A}} & 33 & 14 & 678 \\ \mathrm{Ru} & 19 & 14 & 2296\end{array}$

Tolerant, $0.58 \mathrm{mg} / \mathrm{kg} / \mathrm{wk}$ dosage

\begin{tabular}{|c|c|c|c|}
\hline $\mathrm{Pe}$ & 23 & 14 & 0.585 \\
\hline CyA & 15 & 19 & 0.627 \\
\hline $\mathrm{Ct}^{\mathrm{A}}$ & 18 & 36 & 1.05 \\
\hline $\mathrm{Cu}^{\mathrm{A}}$ & 18 & 36 & 1.36 \\
\hline $\mathrm{Sa}$ & 13 & 14 & 2.51 \\
\hline$U r^{A}$ & 24 & 44 & 5.77 \\
\hline $\mathrm{Ad}^{\mathrm{A}}$ & 25 & 44 & 6.43 \\
\hline$B d^{A}$ & 18 & 23 & 9.92 \\
\hline$E I^{A, B}$ & 13 & 26 & 16.1 \\
\hline \multicolumn{4}{|c|}{ Nontolerant, 2 mg/kg/wk dosage } \\
\hline Ma & 13 & 11 & 58.8 \\
\hline $\mathrm{Ea}$ & 20 & 13 & 317 \\
\hline Op & 10 & 11 & 395 \\
\hline \multicolumn{4}{|c|}{ Tolerant, 2 mg/kg/wk dosage } \\
\hline Fs & 17 & 13 & 0.978 \\
\hline Fo & 17 & 13 & 1.23 \\
\hline Ec & 20 & 13 & 4.18 \\
\hline
\end{tabular}

${ }^{A}$ Also received intrathecal rhIDU. ${ }^{B}$ El did not receive immunosuppression but was nonetheless tolerant to rhIDU.

with recombinant human arylsulfatase B (Naglazyme, galsulfase) ERT for MPS VI, or Maroteaux-Lamy syndrome (7). The breadth and importance of the effect of antibodies is difficult to discern in human patients, however, due to the heterogeneity of the clinical disease and the degree of ERT response; the confounding effect of genotype on both clinical severity and degree of immune response; as well as the relatively small number of patients that do not make any antibodies, which limits the potential for comparisons. Whether prevention of the antibody response to ERT could improve the efficacy of long-term treatment is currently not known. The MPS I patients on ERT for more than 6 years all have minimal or no antibodies against rhIDU (13).

There is evidence in animal models that antibodies may partially neutralize the effect of ERT by reducing the efficiency of uptake and redirecting the enzyme to other target tissues (14-16). Until now, an accurate assessment of the true effect of these antibodies on efficacy has been limited by the inability to create immune-tolerant animals with genotype and lysosomal storage identical to those of antibodyproducing MPS I animals that would allow for comparison of ERT efficacy by detailed analysis of tissue uptake and distribution.

We recently reported a new method for inducing antigen-specific immune tolerance to lysosomal enzymes in the canine model of MPS I (17). Here, we utilized this specific tolerance induction method to produce MPS I canines that are immune tolerant to rhIDU and then compared the impact of immune tolerance on treatment effectiveness with that in MPS I canines that were nontolerant to rhIDU. We found that canines that did not make significant amounts of antibody against rhIDU had significantly improved uptake of rhIDU and substantially greater GAG reduction in nearly all tissues and near normalization in pathologic appearance in the examined tissues. These results may have important clinical implications for many patients receiving ERT for the treatment of lysosomal storage diseases and suggest that optimal ERT will require the induction of immune tolerance to recombinant enzyme therapies.

\section{Results}

Successful induction of immune tolerance. The characteristics of the MPS I dogs used in the study are summarized in Table 1. Eleven MPS I dogs were successfully made immune tolerant to rhIDU using the 60-day immunosuppressive regimen (cyclosporine A and azathioprine) coupled with weekly infusions of low-dose $(0.056 \mathrm{mg} / \mathrm{kg} / \mathrm{wk}) \mathrm{rhIDU}$ as previously described (17). One additional MPS I dog (El) remained tolerant to rhIDU throughout the study period without immune suppression. All immunosuppressives were discontinued by 60 days into the regimen. Low-dose infusions were continued for a total of 12 weeks in the original method, and then the dose was ramped up to $0.58 \mathrm{mg} / \mathrm{kg} / \mathrm{wk}$ rhIDU. A weekly i.v. dose of $0.58 \mathrm{mg} / \mathrm{kg}$ provided in a 3-hour infusion is the same dose and regimen approved by the FDA for treatment of MPS I patients. Immune tolerance was defined as a serum anti-iduronidase titer of less than $20 \mathrm{OD}$ units/ $\mu \mathrm{l}$, and non-tolerance was any titer above this value. The less than $20 \mathrm{OD}$ units/ $\mu$ l tolerance criterion was operationally defined based upon the limit of the range of low titers achieved with the 60-day tolerance regimen and the in vitro uptake inhibition that showed less than $10 \%$ inhibition (17). Tolerant dogs received 14-44 weeks (mean, $24.6 \pm 12.3$ weeks) of full- or high-dose i.v. rhIDU and had a mean end-study antiiduronidase antibody titer of $4.23 \pm 4.74 \mathrm{OD}$ units/ $\mu \mathrm{l}$, and in general, the antibody levels showed at most small increases in the early 12-week time frame and remained steadily low thereafter. Twelve MPS I dogs were not tolerant to rhIDU. Nontolerant dogs developed a high mean antibody titer of $376 \pm 637$ OD units/ $\mu$ l after 9-40 weeks (mean $19.1 \pm 7.54$ weeks) of full- or high-dose i.v. rhIDU. The titers in these dogs steadily rose over the first $12-16$ weeks and continued rising slowly thereafter. Of these nontolerant canines, 6 had intermediate titers of 28.4-113 OD units/ $\mu$, with a mean of 66.0 OD units/ $\mu$ l. Five of these 6 dogs had received alternate, shorter (21-45 days) tolerance regimens that did not induce complete tolerance as defined here ( $<20$ OD units/ $\mu \mathrm{l})$, but this often resulted in lower titers than in nontolerized canines (30-100 OD units/ $\mu \mathrm{l})$. No dog receiving the originally published 60 -day tolerance regimen failed to become tolerant to rhIDU.

Safety parameters including body weight, complete blood counts, serum chemistries, urinalysis, renal function, and hepatic function were assessed in the animals. Two animals ( 1 tolerant and 1 nontolerant) experienced anaphylactoid reactions to i.v. rhIDU, as have treated MPS I dogs reported in previous experiments $(8,18)$. Tolerant animals gained more weight than their nontolerant counterparts $(1.52 \pm 1.09 \mathrm{~kg}$ vs. $0.30 \pm 1.00 \mathrm{~kg} ; P=0.009)$. Eleven of $16 \mathrm{dogs}$ receiving cyclosporine and azathioprine developed low serum magnesium levels, a recognized complication of cyclosporine therapy, which in 2 cases was treated with magnesium supplementation. One dog receiving cyclosporine and azathioprine developed anemia. 


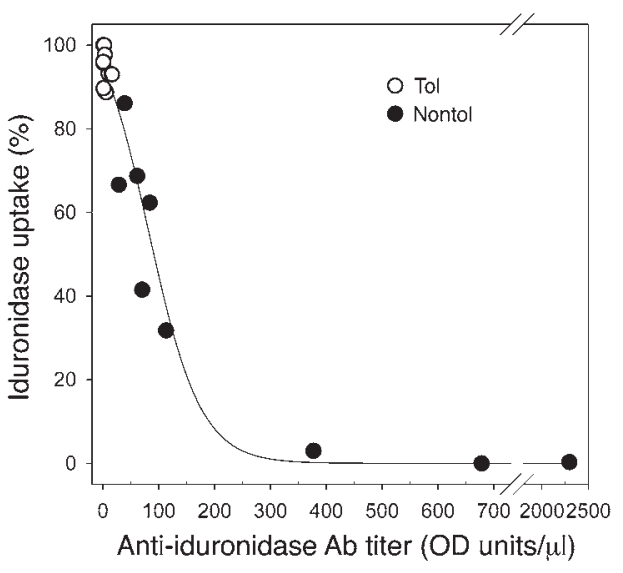

No dogs developed significant elevations in blood urea nitrogen or creatinine during the treatment period, and no dogs had proteinuria. There was no difference in weight gain or other safety parameters between lower- and higher-titer nontolerant dogs.

Antibodies interfere with mannose 6-phosphate receptor-mediated uptake. An in vitro uptake assay was used to determine whether the immune sera contained antibodies that would prevent mannose 6-phosphate receptor-mediated uptake into human MPS I fibroblasts. The data showed that preincubation of rhIDU with antiiduronidase antibodies present in the sera of nontolerant dogs proportionally reduced the uptake of this enzyme once applied to Hurler fibroblasts (Figure 1). The correlation closely followed a sigmoidal distribution (Figure $1 ; r^{2}=0.96 ; P<0.0001$ ). A sharp decrease in uptake occurred at fairly low anti-iduronidase antibody titers, suggesting that even moderate levels of antibodies can have a profound effect on mannose 6-phosphate receptor-mediated uptake. Sera from 2 dogs ( $\mathrm{El}$ and $\mathrm{Et}$ ) were also studied at interim time points; the uptake inhibition corresponded to the titer at the time point studied (data not shown). To confirm that the inhibition was due to antibody, serum from a high-titer nontolerant $\operatorname{dog}(\mathrm{Um})$ was depleted of IgG antibody by a protein A column

\section{Figure 1}

Uptake inhibition of iduronidase by anti-iduronidase antibodies in vitro. Tolerant (Tol) dogs have very low or undetectable antibody levels and show little to no uptake inhibition. At the higher antibody titers in nontolerant (Nontol) dogs, there is near-total inhibition of enzyme uptake into cells. The degree of uptake inhibition corresponds to antibody levels in a sigmoidal distribution $\left(r^{2}=0.96\right)$.

and then was no longer able to inhibit rhIDU uptake (data not shown). These data provide a potential explanation for an inhibitory effect on efficacy that depends on the antibody's interference with receptor-mediated uptake, rather than more commonly considered action of enzyme-neutralizing antibodies, which are rarely observed in MPS ERT studies.

Immune tolerance to rbIDU improves enzyme distribution and uptake by tissues. To address how the antibodies might affect rhIDU distribution and efficacy, tolerant and nontolerant MPS I dogs were treated with $0.58 \mathrm{mg} / \mathrm{kg}$ i.v. rhIDU once per week as described in Methods and analyzed for enzyme activity to assess the distribution and uptake of rhIDU (Table 2 and Figure 2A). When the tissues were analyzed, tolerant canines had significantly higher rhIDU levels (mean, 260\%) than nontolerant canines in most tissues that lack high concentrations of tissue macrophages, including renal cortex, renal medulla, lung, heart valve, myocardium, and rib cartilage (Table 2 and Figure 2B). In contrast, enzyme levels were relatively lower in tolerant dogs than nontolerant dogs (mean 43\%) in the macrophage-enriched (reticuloendothelial) tissues, including liver, spleen, and lymph nodes, consistent with the increase in antibody-mediated uptake via macrophage-like cell types. The obvious explanation may be that the antibodies redirected enzyme to the $\mathrm{Fc}$ receptors on tissue macrophages that are abundant within these tissues and away from other tissues.

To assess the effect of a higher dose in the presence or absence of antibodies, 3 nontolerant and 3 tolerant dogs received a 4-fold higher dose of rhIDU ( $2 \mathrm{mg} / \mathrm{kg}$ per week). Increasing the weekly dose to $2 \mathrm{mg} / \mathrm{kg}$ rhIDU increased mean tissue iduronidase levels in non-macrophage-rich tissues in tolerant canines to a greater extent than in nontolerant canines (mean, 440\%; Table 2 and Figure 2C).

\section{Table 2}

Tissue iduronidase levels in tolerant and nontolerant MPS I dogs receiving i.v. rhIDU

Tissue

$\begin{array}{lc} & \begin{array}{c}\text { Nontolerant } \\ (\boldsymbol{n}=\mathbf{9})\end{array} \\ \text { Liver } & 327 \pm 71.9 \\ \text { Spleen } & 79.9 \pm 111 \\ \text { Lymph node } & 11.0 \pm 25.6 \\ \text { Mean ratio } & - \\ & \\ \text { Lung } & 1.04 \pm 2.50 \\ \text { Heart valve } & 1.04 \pm 0.893 \\ \text { Myocardium } & 0.135 \pm 0.091 \\ \text { Renal cortex } & 3.45 \pm 3.08 \\ \text { Renal medulla } & 1.07 \pm 0.545 \\ \text { Synovium } & 0.720 \pm 0.856 \\ \text { Cartilage (rib) } & 1.30 \pm 1.36\end{array}$

$0.58 \mathrm{mg} / \mathrm{kg} / \mathrm{wk}$

Tolerant
$(n=9)$

$171 \pm 76.4$

$46.8 \pm 37.5$

$2.05 \pm 2.06$

$-$
$2.46 \pm 2.18$
$2.53 \pm 3.96$
$0.293 \pm 0.164$
$9.81 \pm 8.47$
$5.47 \pm 4.06$
$0.888 \pm 0.865$
$2.65 \pm 3.51$

$\begin{gathered}\text { Tolerant/ } \\ \text { nontolerant }\end{gathered}$
$52 \%$
$59 \%$
$19 \%$

$43 \%$

$240 \%$

$240 \%$

$220 \%$

$280 \%$

$510 \%$

$120 \%$

$200 \%$
$2.0 \mathrm{mg} / \mathrm{kg} / \mathrm{wk}$

$\begin{gathered}\text { Nontolerant } \\ (\boldsymbol{n}=3)\end{gathered}$
$974 \pm 338$
$479 \pm 598$
$10.6 \pm 4.06$

Tolerant
$(n=3)$

$716 \pm 228$

$126 \pm 18.1$

$11.9 \pm 0.702$

Tolerant/
nontolerant
$74 \%$
$26 \%$
$110 \%$
$70 \%$
$140 \%$
$730 \%$
$220 \%$
$160 \%$
$1,600 \%$
$150 \%$
$110 \%$

$14.7 \pm 1.94$

$11.8 \pm 2.61$

$1.05 \pm 0.299$

$25.1 \pm 6.40$

$33.3 \pm 14.2$

$2.41 \pm 2.60$

$4.49 \pm 1.49$

$440 \%$

Mean ratio

$260 \%$

Mean \pm SD tissue iduronidase level shown (in U/mg protein). 
A

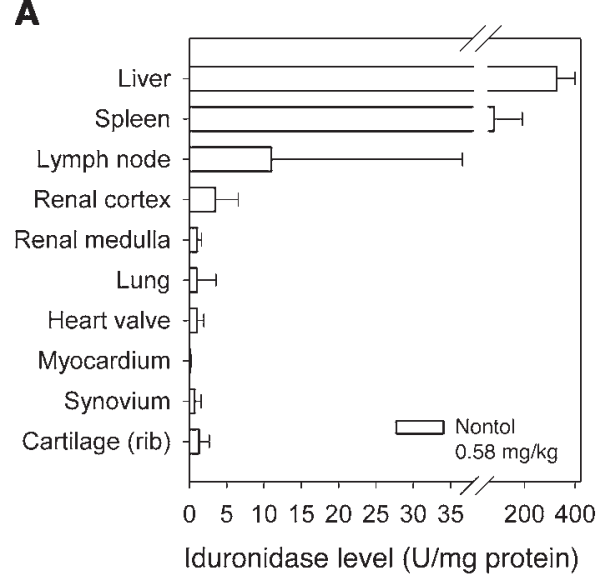

C

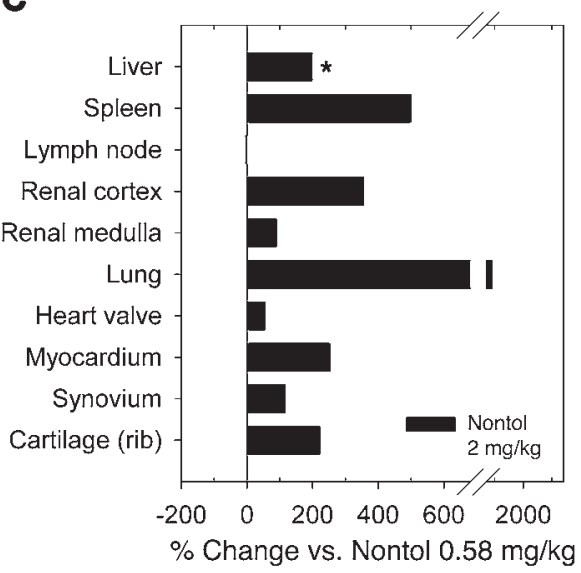

B

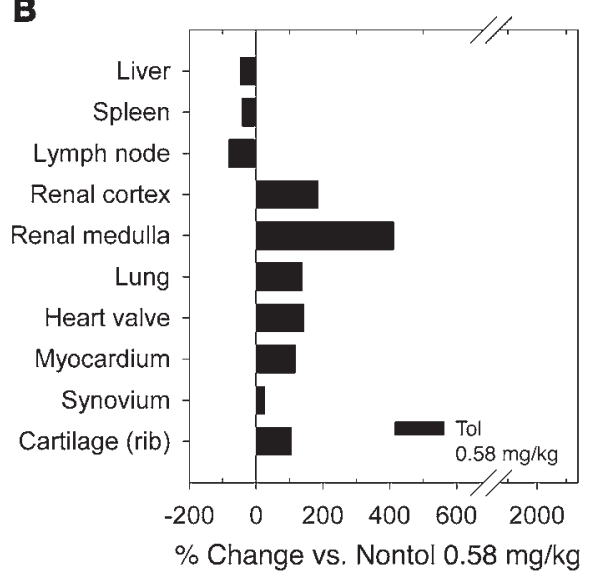

D

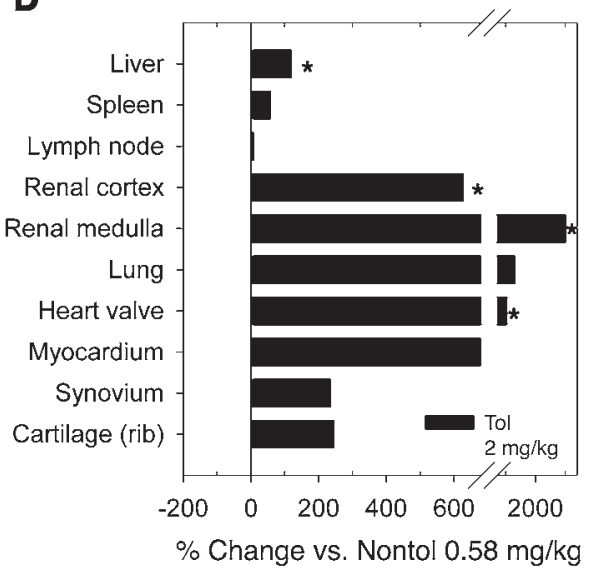

Figure 2

Mean tissue iduronidase in nontolerant MPS I dogs receiving $0.58 \mathrm{mg} / \mathrm{kg}$ i.v. ERT, the current standard of care (A) was compared with that achieved with induction of immune tolerance, increased dose, or both (B-D) (expressed as percent change). Percent change in mean tissue iduronidase levels in tolerant MPS I dogs receiving $0.58 \mathrm{mg} / \mathrm{kg}$ i.v. ERT (B), nontolerant MPS I dogs receiving $2 \mathrm{mg} / \mathrm{kg}$ i.v. ERT (C), and tolerant MPS I dogs receiving $2 \mathrm{mg} / \mathrm{kg}$ i.v. ERT (D). Percent change is measured against mean iduronidase levels in nontolerant MPS I dogs treated with the clinically used $0.58-\mathrm{mg} / \mathrm{kg}$ i.v. ERT (A). ${ }^{*} P<0.05$, statistically significant versus nontolerant, $0.58 \mathrm{mg} / \mathrm{kg} / \mathrm{wk}$.
The levels achieved were on par with or even higher than those achieved with immune tolerance at the lower $0.58-\mathrm{mg} / \mathrm{kg}$ dose. Combining immune tolerance with the higher, $2-\mathrm{mg} / \mathrm{kg}$ weekly dose achieved iduronidase levels that were much higher in renal cortex, renal medulla, lung, heart valve, myocardium, and rib cartilage, reaching enzyme levels approximately 2- to 6-fold higher than in the lower dose-treated tolerant canines and 3.5- to 31-fold higher than those seen in the lower dose-treated nontolerant dogs (Table 2 and Figure 2D).

Immune tolerance improves efficacy of ERT in reducing tissue GAG levels. All treated canines had substantial reductions in tissue GAG compared with untreated canines (Table 3 and Figure 3). Tolerant canines receiving weekly $0.58 \mathrm{mg} / \mathrm{kg}$ i.v. rhIDU had a mean $44 \%$ further reduction in mean GAG storage level beyond the reduction observed in nontolerant canines in the 9 tissues studied (Table 3). In many tissues, the individual tolerant canines achieved GAG levels close to normal tissue levels that were not achievable in nontolerant canines, although the very high level of GAG stored in the kidney and heart valve did not fully decrease to normal levels.

Increasing the dose can overcome the effect of antibodies, though less efficiently than inducing immune tolerance. Absolute rhIDU levels increased to a greater extent with a higher, $2.0-\mathrm{mg} / \mathrm{kg} / \mathrm{wk}$ dose of rhIDU in nontolerant canines than with induction of immune tolerance and treatment at the lower $0.58-\mathrm{mg} / \mathrm{kg} / \mathrm{wk}$ dose (Table 2 and Figure 2), but the effect on GAG storage was not as great (Table 3 and Figure 3). Immune tolerance was more effective than a higher dose in reducing mean GAG storage in almost all tissues studied (Table 3, fourth versus sixth data column). The effect was particularly pronounced in organs with lower levels of reticuloendothelial cells (renal cortex, renal medulla, and lung) and less pronounced in organs with high reticuloendothelial cell content (liver, spleen, lymph nodes; Figure 3). In renal cortex and lung, mean GAG storage levels in tolerant dogs treated with the higher, $2-\mathrm{mg} / \mathrm{kg}$ dose reached the normal range, though heart valve continued to have above-normal GAG levels (Table 3).

Urinary $G A G$ reduction improves substantially with immune tolerance. Urinary GAG measurement is used in patients as an accessible marker for enzyme action in reducing lysosomal storage with ERT. In some patients with high antibody levels, urinary GAG excretion is reduced to a lesser extent than in patients without antibodies. In nontolerant MPS I dogs receiving an $0.58-\mathrm{mg} / \mathrm{kg}$ dose, urinary GAG excretion decreased by a mean of $59.8 \%( \pm 13.1 \%)$, comparable to the $54 \%-70 \%$ reduction observed in patients with antibodies against rhIDU treated for varying times with $\operatorname{rhIDU}(5,10)$. Increasing the dose of i.v. rhIDU 4-fold to $2 \mathrm{mg} / \mathrm{kg}$ in the absence of immune tolerance was not substantially more effective at reducing urinary GAG excretion $(66.1 \% \pm 18.9 \%)$. If immune tolerance was induced, urinary GAG excretion decreased $86.0 \%( \pm 7.08 \%)$, which was significantly greater than the $59.8 \%$ reduction observed with nontolerant dogs at the same $0.58-\mathrm{mg} / \mathrm{kg}$ dose $(P<0.01$; Table 4$)$. Differences persisted after adjusting for age. Combining immune tolerance with the $2-\mathrm{mg} / \mathrm{kg}$ dose led to the greatest reduction in urinary GAG excretion $(93.2 \% \pm 2.25 \%)$, though the incremental benefit above tolerance with the $0.58-\mathrm{mg} / \mathrm{kg}$ dose was only approximately $7.2 \%$ 


\section{Table 3}

Tissue GAG levels ( $\mu \mathrm{g} / \mathrm{mg}$ dry weight) MPS I canines receiving i.v. rhIDU

\begin{tabular}{|c|c|c|c|c|c|c|c|c|}
\hline \multirow[b]{2}{*}{ Tissue } & \multirow[b]{2}{*}{$\begin{array}{c}\text { Normal } \\
(n=6)\end{array}$} & \multirow[b]{2}{*}{$\begin{array}{l}\text { Untreated MPS I } \\
\qquad(n=3)\end{array}$} & \multicolumn{3}{|c|}{$0.58 \mathrm{mg} / \mathrm{kg} / \mathrm{wk}$} & \multicolumn{3}{|c|}{$2.0 \mathrm{mg} / \mathrm{kg} / \mathrm{wk}$} \\
\hline & & & $\begin{array}{l}\text { Nontolerant }{ }^{A} \\
\quad(n=9)\end{array}$ & $\begin{array}{c}\text { Tolerant }^{A} \\
(n=9)\end{array}$ & $\begin{array}{l}\text { Further } \\
\text { storage } \\
\text { reduction }\end{array}$ & $\begin{array}{l}\text { Nontolerant } \\
\quad(n=3)\end{array}$ & $\begin{array}{l}\text { Tolerant } \\
(n=3)\end{array}$ & $\begin{array}{l}\text { Further } \\
\text { storage } \\
\text { reduction }\end{array}$ \\
\hline Liver & $1.87 \pm 0.555$ & $28.6 \pm 6.81$ & $4.61 \pm 1.43$ & $2.37^{B} \pm 0.566$ & $49 \%$ & $3.14 \pm 0.728$ & $4.02 \pm 0.485$ & $-28 \%$ \\
\hline Spleen & $2.01 \pm 0.374$ & $23.4 \pm 4.21$ & $3.90 \pm 1.40$ & $2.33^{B} \pm 0.800$ & $40 \%$ & $5.39 \pm 2.06$ & $3.44 \pm 0.136$ & $36 \%$ \\
\hline Lymph node & $4.30 \pm 2.85$ & $40.9 \pm 20.4$ & $13.4 \pm 4.63$ & $5.18^{B} \pm 2.51$ & $61 \%$ & $8.74 \pm 4.14$ & $7.89 \pm 1.89$ & $9.7 \%$ \\
\hline Renal cortex & $3.55 \pm 0.145$ & $35.8 \pm 2.55$ & $18.5 \pm 6.52$ & $7.02^{\mathrm{B}} \pm 3.96$ & $62 \%$ & $13.6 \pm 8.86$ & $3.49 \mathrm{~B} \pm 0.545$ & $74 \%$ \\
\hline Renal medulla & $6.93 \pm 2.99$ & $36.0 \pm 20.4$ & $23.8 \pm 7.96$ & $13.7^{\mathrm{B}} \pm 5.21$ & $42 \%$ & $18.0 \pm 1.37$ & $11.4^{\mathrm{B}} \pm 1.70$ & $37 \%$ \\
\hline Lung & $4.23 \pm 1.53$ & $17.9 \pm 6.75$ & $9.39 \pm 2.79$ & $5.12^{B} \pm 2.50$ & $45 \%$ & $9.41 \pm 4.43$ & $4.49^{B} \pm 0.770$ & $52 \%$ \\
\hline Heart valve & $7.72 \pm 2.34$ & $81.1 \pm 28.1$ & $77.5 \pm 11.3$ & $59.0 \pm 24.4$ & $24 \%$ & $68.2 \pm 5.47$ & $68.9 \pm 31.3$ & $-1.0 \%$ \\
\hline Myocardium & $0.305 \pm 0.477$ & $3.14 \pm 0.435$ & $1.53 \pm 0.570$ & $0.902 \pm 0.802$ & $41 \%$ & $1.46 \pm 1.01$ & $1.12 \pm 0.093$ & $23 \%$ \\
\hline Synovium & ND & $14.8 \pm 3.51$ & $6.73 \pm 3.80$ & $4.36 \pm 2.97$ & $35 \%$ & $2.98 \pm 0.410$ & $6.82 \pm 7.26$ & $-130 \%$ \\
\hline Mean change & - & - & - & - & $44 \%$ & - & - & $25 \% c$ \\
\hline
\end{tabular}

Mean tissue GAG levels ( \pm SD) are shown. ${ }^{A}$ Raw values are shown. ${ }^{B}$ Statistically significant versus nontolerant, $0.58 \mathrm{mg} / \mathrm{kg}$. ${ }^{\mathrm{C}} \mathrm{The}$ synovium summary comparison (-130\%) was excluded from the overall, high-dose mean change due to 1 sample in 1 canine with an unexplained, very high GAG storage level $(15.2 \mu \mathrm{g} / \mathrm{mg})$. ND, not determined.

for 4-fold more enzyme. Two of the 3 tolerant MPS I dogs treated with $2 \mathrm{mg} / \mathrm{kg}$ i.v. rhIDU had posttreatment urinary GAG levels at the upper end of the normal range ( 16.5 and $17.6 \mu \mathrm{g} / \mathrm{mg}$ creatinine, respectively; normal range, $7.40-17.6 \mu \mathrm{g} / \mathrm{mg}$ creatinine).

Histopathology shows improved lysosomal storage with immune tolerance. In order to evaluate the pathologic consequences of the increased levels of enzyme and decreased GAG levels at the cellular level, we analyzed the light and electron microscopy of a variety of tissues in the treated canines, including the difficult-to-treat kidney and heart valve tissues. We found that immune tolerance substantially enhanced storage reduction in all tissues examined relative to that in nontolerant canines at the same dose, consistent with the biochemical data. The combination of a higher dose and immune tolerance did further improve storage reduction over immune tolerance alone in some tissues that are most difficult to treat, such as the heart valve.

A detailed semiquantitative pathological determination of lysosomal storage was performed using a 5 -point scale $(0-4$, normal to severe lysosomal storage; Table 5). To score the tissues, the lysosomal storage was evaluated on a series of 50 sections tabulated by individual cell type, with the pathologist blinded to treatment category. Tolerant dogs had mild to no lysosomal storage in most cell types. Histopathology showed the greatest benefit from immune tolerance to be in the kidney and synovium, with improvement also seen in lymph nodes and heart valve in tolerant dogs receiving the higher, $2-\mathrm{mg} / \mathrm{kg}$ dose. The scores for renal lysosomal storage correlated well with the reduction in urinary GAG levels and improved GAG clearance in the kidney measured by biochemical methods.

The enhanced reduction in lysosomal storage scores in tolerant subjects is illustrated in the light micrographs shown in Figure 4. While a nontolerant dog's tissues demonstrated some reduction in renal tubular storage material (Figure 4, left column), immune tolerance enhanced the reduction so that renal tubular epithelial cells appeared essentially normal. Tolerant dogs had distinctly improved GAG clearance compared with nontolerant dogs in interstitial "foam cells" (GAG-laden macrophages), proximal tubules, and, in particular, distal cortical tubules. Note also that the nontolerant dogs with more moderate antibody levels did have a somewhat greater reduction in lysosomal storage in the cortical interstitial macrophages but not in the tubules and had urinary GAG excretion similar to that of the nontolerant group (data not shown). Even a moderate level of antibodies has an effect on renal storage reduction at the cellular level.

Synovial histopathology (Figure 4, middle column) showed a high degree of vacuolation in lining cells and subjacent collections of macrophages in the untreated MPS I dog. In the nontolerant dog, lining cells contained a modest level of cytoplasmic storage, and subjacent "foam cells" persisted. Immune tolerance improves the histopathology of the synovium, and at the $2-\mathrm{mg} / \mathrm{kg}$ dose, the cellular morphology was indistinguishable from that of the normal dog.

In the heart valve, we had not previously observed good evidence of storage reduction in dogs receiving i.v. ERT. In these canines with preexisting valve thickening, the combination of immune tolerance with a 4-fold increase in dose did reduce GAG storage dramatically to a normal histological appearance (Figure 4, right column). Quantitative biochemical GAG storage measures did not completely reflect this change, due perhaps to the presence of excess extracellular GAG storage in this connective tissue, where it cannot be taken up and metabolized in the lysosome after ERT.

\section{Discussion}

We have shown that a reduction in anti-iduronidase antibodies through the induction of rhIDU-specific immune tolerance improves enzyme delivery, uptake into tissues, and clearance of lysosomal storage in the MPS I canine model. The inhibitory effect of antibodies on mannose 6-phosphate-receptor-mediated uptake into cells in vitro may provide an explanation for this in vivo effect. Either the induction of immune tolerance or a higher dose of i.v. rhIDU $(2 \mathrm{mg} / \mathrm{kg} / \mathrm{wk})$ could achieve tissue iduronidase levels higher than those observed in nontolerant canines at $0.58 \mathrm{mg} / \mathrm{kg} / \mathrm{wk}$; however, GAG storage was improved with immune tolerance to a greater extent than with the increased dose alone, suggesting that the immune response is a more important factor. Urinary GAG excretion also improved more substantially in tolerant dogs than in nontolerant dogs treated with a higher dose. Finally, the combination of immune tolerance and the higher, $2-\mathrm{mg} / \mathrm{kg} / \mathrm{wk}$ dose of rhIDU achieved very high iduronidase levels in some tissues, fur- 
A

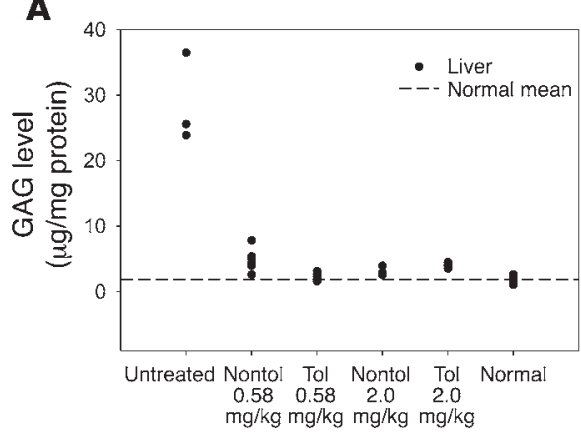

B

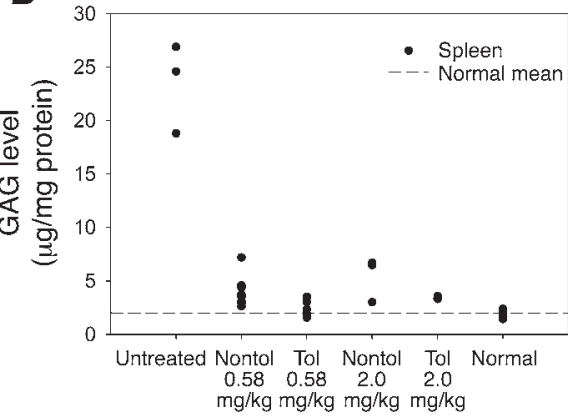

E

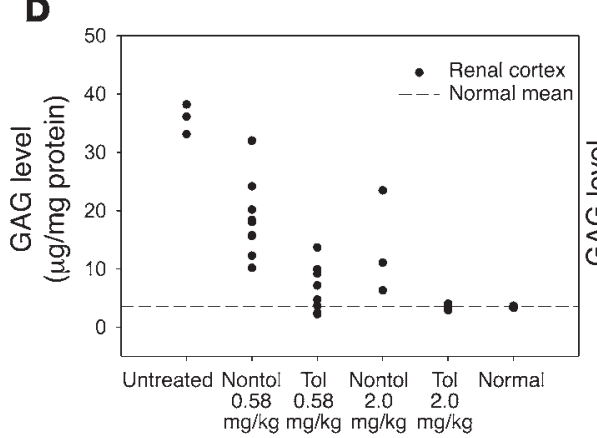

C

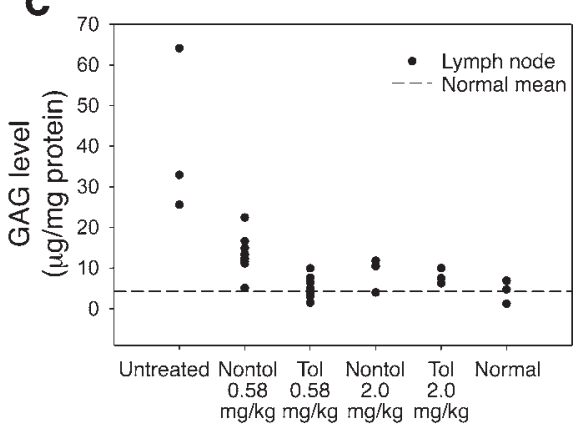

$\mathbf{F}$

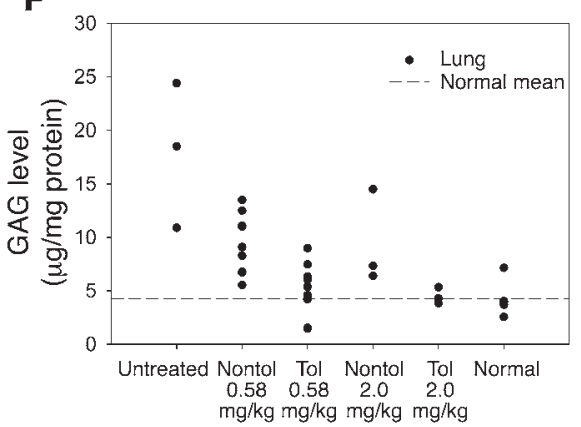

Figure 3

Tissue GAG reduction after ERT with and without tolerance or higher-dose therapy. In organs with large amounts of nonspecific uptake by reticuloendothelial cells (liver, spleen, and lymph node; A-C), there is less of a difference in GAG storage reduction with dose or tolerance status. In organs without high levels of reticuloendothelial cells (renal cortex, renal medulla, and lung; D-F), tolerance enhances GAG storage reduction to a greater extent than an increased dose.

ther reduced mean GAG storage, normalized urinary GAG excretion, and improved histopathology in some of the hardest-to-treat tissues, such as the heart valve.

In vitro experiments showed that anti-iduronidase antibodies inhibited rhIDU uptake into cells in a concentration-dependent fashion. The inhibitory relationship was sigmoidal, with a steep decline in uptake at relatively low antibody titers. In vivo, tissue iduronidase levels were lower in nontolerant dogs (which had higher anti-iduronidase antibody titers) than in tolerant dogs treated with i.v. rhIDU. Previous work has shown that rhIDU enters most cells by means of the mannose 6-phosphate receptor but that reticuloendothelial cells such as macrophages do not require this receptor for uptake $(19,20)$. In addition to receptors for mannose 6-phosphate and mannose, these cell types have $\mathrm{Fc}$ receptors for antibodies. Thus, in the liver, spleen, and lymph nodes, rhIDU uptake is relatively preserved even in nontolerant dogs, though the distribution may be enhanced toward the tissue macrophages. In these tissues, immune tolerance does not increase absolute iduronidase levels but may lead to a more even distribution of enzyme among cell types that allows for a greater reduction in GAG storage levels in liver, spleen, and lymph nodes in tolerant versus nontolerant dogs.

In hard-to-treat tissues such as the synovium and heart valve, treatment results were improved with tolerance but improved further if a higher dose was also used. Iduronidase levels were generally increased in tolerant dogs, and indeed very high levels were achieved in the heart valve when tolerance was combined with an increase in rhIDU dose to $2 \mathrm{mg} / \mathrm{kg} / \mathrm{wk}$. Lysosomal storage in the synovium as assessed by histopathology improved with tolerance at the $0.58-\mathrm{mg} / \mathrm{kg}$ dose and resolved at the $2-\mathrm{mg} / \mathrm{kg}$ dose. MPS I dogs have joint laxity rather than the joint restriction seen in human patients, and so no clinical correlation of the joint disease could be evaluated. Histopathology of the heart valve showed some reduction in intracellular GAG storage in the tolerant MPS I dogs that received $0.58 \mathrm{mg} / \mathrm{kg} / \mathrm{wk}$ but much more dramatic reductions at the higher dose of $2 \mathrm{mg} / \mathrm{kg} / \mathrm{wk}$ i.v. rhIDU. In both the heart valve and synovium, quantitative measures of overall GAG storage did not change, possibly reflecting the relatively high levels of extracellular GAG present that is not accessible to lysosomal rhIDU. This excess extracellular GAG may be more difficult to metabolize once it has accumulated or it may require longer treatment periods to remodel into a more normal matrix. These results showing improved treatment at higher doses are limited by the small number of dogs receiving the higher, $2-\mathrm{mg} / \mathrm{kg}$ dose, though the results were consistent among the animals. The reduction in intracellular GAG storage in tolerant MPS I dogs receiving a high dose of i.v. rhIDU (4-fold greater than the approved dose), observed for the first time to our knowledge in the present study, suggests that heart valve disease may be treatable or preventable.

In MPS I patients, ERT with i.v. rhIDU improves urine GAG excretion, with a mean of between $54 \%$ and $63 \%$, dependent to some degree on the immune response (5). The association between higher anti-iduronidase antibody levels and higher urinary GAG levels has recently been shown in young patients with more severe Hurler MPS I (MPS IH) receiving i.v. rhIDU; higher-titer patients with null genotypes most often had a $50 \%-60 \%$ reduction in urinary GAG, whereas the low-titer missense patients had a higher reduction of greater than $80 \%$ (12). In our study of MPS I dogs, animals that were not tolerant to rhIDU had urine GAG reduction 


\section{Table 4}

Urinary GAG measurement in tolerant and nontolerant MPS I dogs

\begin{tabular}{|c|c|c|c|c|c|}
\hline Status & $\begin{array}{l}\text { Normal } \\
(n=13)\end{array}$ & $\begin{array}{c}\text { Nontolerant, } \\
0.58 \mathrm{mg} / \mathrm{kg}(n=9)^{\mathrm{A}}\end{array}$ & $\begin{array}{c}\text { Tolerant, } \\
0.58 \mathrm{mg} / \mathrm{kg}(n=7)^{\mathrm{A}}\end{array}$ & $\begin{array}{l}\text { Nontolerant, } \\
2 \mathrm{mg} / \mathrm{kg}(n=3)\end{array}$ & $\begin{array}{c}\text { Tolerant, } \\
2 \mathrm{mg} / \mathrm{kg}(n=3)\end{array}$ \\
\hline Pretreatment & $10.8 \pm 3.39$ & $246 \pm 125$ & $488 \pm 183$ & $240 \pm 51.3$ & $301 \pm 14.7$ \\
\hline Posttreatment & - & $88.5 \pm 20.5$ & $62.9 \pm 26.8$ & $83.1 \pm 58.2$ & $20.4 \pm 5.89$ \\
\hline Change (\%) & - & $59.8 \pm 13.1$ & $\begin{array}{l}86.0 \pm 7.08 \\
P=0.003^{B}\end{array}$ & $\begin{array}{c}66.1 \pm 18.9 \% \\
P=\mathrm{NS}\end{array}$ & $\begin{array}{l}93.2 \pm 2.25 \% \\
P=0.0017^{B}\end{array}$ \\
\hline
\end{tabular}

GAG levels are expressed in micrograms per milligram creatinine. Urine GAG levels were not available for 2 dogs (Pe, Sa). ${ }^{A}$ Raw values are shown.

BStatistically significant $P$ values compared with nontolerant $0.58 \mathrm{mg} / \mathrm{kg}$. Differences remained significant after adjustments for age were made.

of roughly $60 \%$, similar to results seen in patients. When the dose was increased to $2 \mathrm{mg} / \mathrm{kg}$ without immune tolerance, urine GAG reduction was enhanced slightly, to $66 \%$. However, with induction of tolerance to rhIDU in MPS I dogs, urinary GAG reduction was improved to $86 \%$, and further to $93 \%$ if tolerance was combined with a 4-fold increase in dose. The improved urinary GAG reduction with immune tolerance reflects improved clearance of renal storage within the tubules, based on our pathologic evaluations here and previously in this model.

Anti-iduronidase antibodies are present in the majority of MPS I patients treated with rhIDU. Our study suggests that while rhIDU continues to be effective in patients who make antibodies, these antibodies may have an impact on the enzyme's maximal potential efficacy. The difference in efficacy may be minimal in easierto-treat organs such as liver, but in those more difficult-to-treat organs such as the kidney, particularly the renal medulla, there is a relationship between antibody level and reduced clearance of GAG storage. By inducing immune tolerance to iduronidase and preventing the immune response, the effectiveness of treatment may be enhanced in these difficult-to-treat and clinically important tissues, including heart valve, joints, and other connective tissues. Tolerance may benefit severe as well as attenuated MPS I patients, given that a substantial antibody titer is induced in more than $90 \%$ of patients, though higher titers are reached in null severe Hurler-type patients $(10,12)$. While anti-iduronidase antibody titers in MPS I patients on ERT do decrease with time, only about $30 \%$ become fully tolerant over a 30 -year period (21), though none of the double-null genotype patients who are most similar to the null MPS I canines tolerize completely $(11,12)$. Induction of tolerance early in the treatment course could also improve treatment outcome during the initial treatment period even if tolerance were eventually to occur spontaneously over several years in some patients. Determining whether this tolerance induction method could improve ERT in human MPS I patients will be the focus of a clinical study that is currently planned.

For other enzyme replacement therapies, antibodies are commonly induced and may similarly impact efficacy to some degree. Studies of the immune tolerance method used here using $\alpha$-glucosidase, the enzyme deficient in Pompe disease, also showed a similar induction of tolerance in normal canines (17). If this method of inducing tolerance can be successfully applied to human lysosomal disease patients planning to initiate ERT, the reduced antibody response could improve the long-term outcome of ERT, particularly in Hunter, Maroteaux-Lamy, Fabry, or Pompe patients with null or low antigen level genotypes who may mount stronger immune responses.

\section{Methods}

The canine MPS I colony is a beagle/Plott hound mix, bred and maintained at the Los Angeles Biomedical Research Institute at Harbor-UCLA Medical Center, an Association for Assessment and Accreditation of Laboratory Animal Care-accredited facility. All protocols were approved by the Animal Care and Use Committee of Harbor-UCLA Medical Center.

Induction of tolerance. Dogs affected with canine MPS I received oral cyclosporine and azathioprine combined with low-dose $(0.056 \mathrm{mg} / \mathrm{kg})$ i.v. rhIDU for 60 days to induce tolerance as described by Kakkis et al. (17). Five of the nontolerant MPS I dogs ( $\mathrm{Ni}, \mathrm{Ub}, \mathrm{Ul}, \mathrm{Xy}, \mathrm{Xb})$ also received cyclosporine and azathioprine, at similar doses but for shorter duration. These dogs had been given the shorter (21-45 days) alternate tolerance

\section{Table 5}

Histopathologic scoring system for lysosomal storage

\begin{tabular}{|c|c|c|c|c|c|c|}
\hline & \multirow{2}{*}{$\begin{array}{l}\text { Untreated } \\
\text { MPS I } \\
(n=3)\end{array}$} & \multicolumn{2}{|c|}{ Nontolerant, $0.58 \mathrm{mg} / \mathrm{kg} / \mathrm{wk}$} & \multirow{2}{*}{$\begin{array}{c}\text { Tolerant, } \\
0.58 / \mathrm{mg} / \mathrm{kg} / \mathrm{wk} \\
(n=9)\end{array}$} & \multirow{2}{*}{$\begin{array}{c}\text { Nontolerant, } \\
2 \mathrm{mg} / \mathrm{kg} / \mathrm{wk} \\
(n=3)\end{array}$} & \multirow{2}{*}{$\begin{array}{c}\text { Tolerant, } \\
2 \mathrm{mg} / \mathrm{kg} / \mathrm{wk} \\
(n=3)\end{array}$} \\
\hline & & $\begin{array}{l}\text { Mod. titer } \\
\quad(n=6)\end{array}$ & $\begin{array}{l}\text { High titer } \\
\quad(n=3)\end{array}$ & & & \\
\hline Liver & $4.00(4-4)$ & $0.00(0-0)$ & $0.17(0-0.5)$ & $0.00(0-0)$ & $0.00(0-0)$ & $0.00(0-0)$ \\
\hline Spleen & $4.00(4-4)$ & $0.04(0-0.25)$ & $0.67(0-2)$ & $0.00(0-0)$ & $0.00(0-0)$ & $0.00(0-0)$ \\
\hline Lymph nodes & $4.00(4-4)$ & $2.58(2-3)$ & $2.50(2-3)$ & $1.28^{A}(0-3)$ & $1.75(0.25-3)$ & $0.17^{A}(0-0.5)$ \\
\hline Lung $^{B}$ & $4.00(4-4)$ & $1.50(1-2)$ & $1.67(1-2)$ & $1.14(0.5-2.5)$ & $1.5^{\mathrm{B}}(1.5)$ & $1.75^{\mathrm{C}}(1.5-2)$ \\
\hline Renal cortex & $4.00(4-4)$ & $1.67(1-3)$ & $2.17(0.5-3)$ & $0.39^{A}(0-2)$ & $1.17(0-3.5)$ & $0.08^{A}(0-0.25)$ \\
\hline Renal tubules (medulla) & $4.00(4-4)$ & $2.67(2-3.5)$ & $2.83(2.5-3)$ & $0.67^{A}(0-3)$ & $1.67^{A}(1-3)$ & $0.00^{A}(0-0)$ \\
\hline Heart valve & $4.00(4-4)$ & $3.33(3-4)$ & $3.67(3-4)$ & $2.22^{\mathrm{A}}(1.5-3)$ & $2.75(2.5-3)$ & $0.42^{A}(0.25-0.5)$ \\
\hline Synoviumc & $4.00(4-4)$ & $1.67(1-2.5)$ & $2.00(1,3)$ & $0.39 A(0-2)$ & $1.17(0-3)$ & $0.00^{A}(0-0)$ \\
\hline
\end{tabular}

Scoring: 0, no GAG storage; 1, mild; 2, moderate; 3, marked; 4, most severe. Mean score and range (parentheses) are presented. Scoring grade is specific for tissue types and not cross-comparable. Moderate titer (Mod. titer): Xb, Xy, Ub, Et, Ni, Ul. High titer: Ye, Um, Ru. AStatistically significant versus nontolerant, $0.58 \mathrm{mg} / \mathrm{kg} / \mathrm{wk}$, mean of moderate and high-titer groups. ${ }^{B}$ Lung data not available for Fo, Ma, and Op. ${ }^{\mathrm{C} S y n o v i u m ~ d a t a ~ n o t ~ a v a i l a b l e ~ f o r ~ Y e . ~}$ 


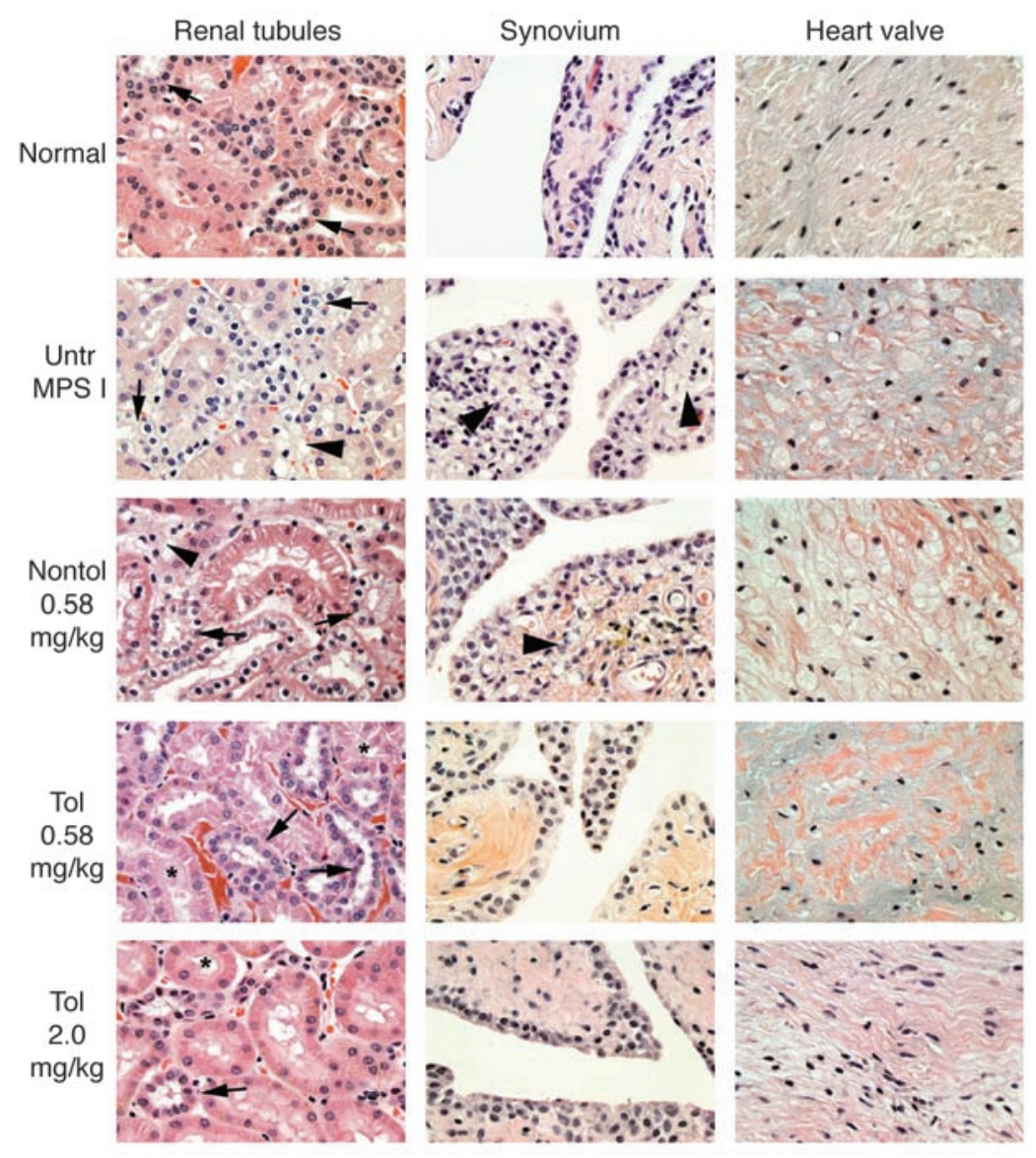

\section{Figure 4}

Pathologic evidence that immune tolerance to ERT enhances reduction of lysosomal storage in treated dogs in kidney, synovium, and mitral valve. Normal renal morphology from unaffected carriers is shown in the top row; arrows indicate epithelium lining distal cortical tubules. The untreated MPS I (Untr MPS I) dogs have swollen, GAG-laden cells lining distal cortical tubules and the synovium and within the mitral valve stroma. Interstitial "foam cells" (macrophages storing GAG) are common. Renal tubular cells from the nontolerant treated (Nontol $0.58 \mathrm{mg} / \mathrm{kg}$ ) dogs have reduced storage, but GAG-laden interstitial macrophages persist. Synovial tissues contain modest amounts of cytoplasmic vacuolation in lining cells and reduced GAG-laden macrophages. Mitral valve storage is prominent. In tolerant dogs treated with 0.58 and $2 \mathrm{mg} / \mathrm{kg}$, storage material is eliminated throughout renal cortical tissues. In the synovium, GAG-laden macrophages are absent and lining cell vacuolation is greatly reduced with low-dose treatment and entirely absent in the tolerant dogs treated at $2 \mathrm{mg} / \mathrm{kg}$. Mitral valve storage is reduced in low dose-treated dogs, and cellular morphology resembles that of normal dogs in the tolerant animals treated with the higher, $2-\mathrm{mg} / \mathrm{kg}$ dose. Arrows indicate distal renal cortical tubules; proximal tubules are marked with asterisks. Arrowheads indicate accumulations of interstitial GAG-laden macrophages. All images show H\&E staining. Original magnification, $\times 400$. regimens, which, unlike the full, 60-day regimen, did not induce complete tolerance to rhIDU. These dogs were nontolerant but had relatively low titers (28.4-113 OD units/ $\mu 1)$. Untreated MPS I and carrier dogs were used as controls.

Administration of i. v. rhIDU. rhIDU was donated by BioMarin at a concentration of $0.58 \mathrm{mg} / \mathrm{ml}$ in formulation buffer $(150 \mathrm{mM} \mathrm{NaCl}, 100 \mathrm{mM}$ sodium phosphate, $0.001 \%$ polysorbate $80, \mathrm{pH} 5.8$ ). For weekly administration, rhIDU was diluted in $0.9 \%$ saline and $1 \mathrm{mg} / \mathrm{ml}$ canine albumin and infused into a cephalic vein over 3 hours once per week throughout the study period. Serum for antibody determinations was collected prior to each infusion. Duration of full-dose i.v. rhIDU ranged from 9 to 44 weeks (Table 1). This range occurred because several dogs were also receiving intrathecal rhIDU in other studies of varying duration $(22,23)$, but in our experience $(8,18)$, the time of treatment beyond a 3 -month period does not have a substantial effect on tissue rhIDU and GAG levels achieved, and there was an overlapping range of treatment time in the treatment groups.

Clinical assessments. For tolerance induction by the published method (17), blood cyclosporine A levels were assessed using trough samples beginning on days 5-9 of cyclosporine A administration. Cyclosporine A doses were adjusted to obtain a trough level of at least $400 \mathrm{ng} / \mathrm{ml}$ before initiation of low-dose rhIDU infusions. Weekly complete blood cell counts, leukocyte differentials, blood chemistry assessments, and total immunoglobulin assays were performed on all animals throughout the study period. Urinalysis and urine creatinine testing was performed on a weekly basis for the first month and every 3-4 weeks thereafter.

Determination of specific antibody ELISA titers in canine serum. ELISA assays for anti-iduronidase antibodies were conducted with goat anti-canine IgG (SouthernBiotech), conjugated to alkaline phosphatase as previously described (17). Absorbance at a wavelength of $405 \mathrm{~nm}$ was detected as OD units using a SpectraMAX 340 (Molecular Devices) spectrophotometer. The calculated OD value for any sample was taken from dilutions within the linear signal range.

Determination of uptake inhibition of rhIDU in canine serum samples. Skin fibroblasts from an individual with MPS I Hurler individual (GM 1391; National Institute of General Medical Sciences, Human Genetic Cell Repository, Coriell Institute for Medical Research) were passed to a confluence of $85 \%-95 \%$ in 6-well cell culture cluster plates. rhIDU was diluted to $18 \mathrm{U} / \mathrm{ml}$ in MEM plus $1 \%$ L-glutamine. Preimmune or posttreatment canine serum was added at 1:1,000 dilution and preincubated for 1 hour at room temperature with diluted rhIDU enzyme. The enzyme was diluted to bring its concentration in the uptake assay down to near the $K_{\mathrm{m}}$ for the mannose 6-phosphate receptor (19). Two milliliters of the diluted serum/rhIDU mixture was added to triplicate wells containing confluent Hurler fibroblasts and incubated for 1 hour at $37^{\circ} \mathrm{C}$ and $5 \% \mathrm{CO}_{2}$ and cells harvested by trypsinization. The cell pellet was washed once in cold PBS and resuspended in $60 \mu \mathrm{l}$ of PAD $\left(10 \mathrm{mM} \mathrm{NaPO}_{4}, \mathrm{pH} 5.8,0.02 \%\right.$ sodium azide, $0.1 \mathrm{mM} \mathrm{DTT}$ ) plus $0.1 \%$ Triton X-100, disrupted by sonication, and centrifuged. Iduronidase activity was measured as described below, except that $25 \mu \mathrm{l}$ of supernatant was assayed in $25 \mu \mathrm{l} 50 \mu \mathrm{M}$ 4-methylumbelliferyl $\alpha$-L-iduronide (4-MUI; Calbiochem) at $22^{\circ} \mathrm{C}$ for 1 hour. As an additional control to ascertain that antibodies were the inhibiting component, serum from 1 nontolerant $\operatorname{dog}(\mathrm{Um})$ was then depleted of IgG antibody by passage through four 0.2-ml NAb Protein A Plus Spin Columns (Pierce; Thermo Scientific). This reduced the anti-iduronidase antibody titer to $3.1 \mathrm{OD}$ units/ $\mu$ l. The uptake experiment was then repeated using the antibodydepleted serum to verify the identity of the inhibitor as antibodies. 
Biochemical analyses. Animals were euthanized by barbiturate injection 48 hours after the last rhIDU i.v. infusion. Tissues were harvested immediately, frozen on dry ice, and stored at $-80^{\circ} \mathrm{C}$ until assayed for iduronidase activity and GAG content. Iduronidase activity was assessed using $250 \mu \mathrm{M}$ 4-MUI as previously described (8), except that the incubation temperature was $37^{\circ} \mathrm{C}$ and the incubation time was 1 hour. Urine and tissue GAG was measured using the Alcian blue dye binding method of Bjornssen, modified as previously published (8). Urinary creatinine was quantified using the Roche reagent for creatinine and measured at $500 \mathrm{~nm}$ on a COBAS MIRA chemistry analyzer. Four pretreatment and 4 end-treatment urine samples were taken for measurement of urinary GAG. Pretreatment samples were collected within 4 weeks of ERT. End-treatment samples were collected during the final 2 weeks of ERT.

Pathological determination of GAG storage. Immediately following euthanasia, tissues were fixed in $10 \%(\mathrm{vol} / \mathrm{vol})$ neutral buffered formalin. The sections were stained with $\mathrm{H} \& \mathrm{E}$, and 3 samples from each tissue from each animal were scored in a blinded fashion. A score of 0 represented no storage (comparable to an unaffected control); 1 , mild; 2 , moderate; 3 , marked; and 4 , severe storage (comparable to an untreated affected subject). Three untreated MPS I and 2 normal dogs were used as controls.

Statistics. Mean and SD were calculated in standard fashion. Twotailed, unpaired Student's $t$ test was used to calculate $P$ values, with $P<0.05$ considered significant. The statistics here were used as descrip-

1. Fratantoni, J.C., Hall, C.W., and Neufeld, E.F. 1968. Hurler and Hunter syndromes: mutual correction of the defect in cultured fibroblasts. Science. 162:570-572.

2. Barton, N.W., et al. 1991. Replacement therapy for inherited enzyme deficiency: macrophage-targeted glucocerebrosidase for Gaucher's disease. N. Engl.J. Med. 324:1464-1470.

3. Eng, C.M., et al. 2001. Safety and efficacy of recombinant human alpha-galactosidase A replacement therapy in Fabry's disease. N. Engl. J. Med. 345:9-16.

4. Kishnani, P.S., et al. 2006. Chinese hamster ovary cellderived recombinant human acid alpha-glucosidase in infantile-onset Pompe disease. J. Pediatr. 149:89-97.

5. Kakkis, E.D., et al. 2001. Enzyme-replacement therapy in mucopolysaccharisosis I. N. Engl. J. Med. 344:182-188.

6. Muenzer, J., et al. 2006. A phase II/III clinical study of enzyme replacement therapy with idursulfase in mucopolysaccharidosis II (Hunter syndrome). Genet. Med. 8:465-473.

7. Harmatz, P., et al. 2006. Enzyme replacement therapy for mucopolysaccharidosis VI: A phase 3, randomized, double-blind, placebo-controlled, multinational study of recombinant human $\mathrm{N}$ acetylgalactosamine 4-sulfatase (recombinant human arylsulfatase B or rhASB) and follow-on, open-label extension study. J. Pediatr. 148:533-539.

8. Kakkis, E.D., et al. 1996. Long-term and high-dose trials of enzyme replacement therapy in the canine model of mucopolysaccharidosis I. Biochem. Mol. Med. 58:156-167.
9. Rosenberg, M., Kingma, W., Fitzpatrick, M.A., and Richards, S.M. 1999. Immunosurveillance of alglucerase enzyme therapy for Gaucher patients: induction of humoral tolerance in seroconverted patients after repeat administration. Blood. 93:2081-2088.

10. Wraith, J.E., et al. 2004. Enzyme replacement therapy for mucopolysaccharidosis I: a randomized, double-blinded, placebo-controlled, multinational study of recombinant human alpha-L-iduronidase (laronidase). J. Pediatr. 144:581-588.

11. Kakavanos, R., et al. 2003. Immune tolerance after long-term enzyme-replacement therapy among patients who have mucopolysaccharidosis I. Lancet. 361:1608-1613.

12. Wraith, J.E., et al. 2007. Enzyme replacement therapy in patients who have mucopolysaccharidosis I and are younger than 5 years: results of a multinational study of recombinant human alpha-L-iduronidase (laronidase). Pediatrics. 120:e37-e46.

13. Sifuentes, M., et al. 2007. A follow-up study of MPS I patients treated with laronidase enzyme replacement therapy for 6 years. Mol. Genet. Metab. 90:171-180.

14. Brooks, D.A., King, B.M., Crawley, C., Byers, S., and Hopwood, J.J. 1997. Enzyme replacement therapy in Mucopolysaccharidosis VI: evidence for immune responses and altered efficacy of treatment in animal models. Biochim. Biophys. Acta. 1361:203-216.

15. Brooks, D.A., Hopwood, J.J., and King, B.M. 1998 Immune response to enzyme replacement therapy: clinical signs of hypersensitivity reactions and altered enzyme distribution in a high titre rat model. Biochim. Biophys. Acta. 1407:163-172.

16. Glaros, E.N., et al. 2002. Immune response to enzyme replacement therapy: single epitope control of antigen distribution from circulation. Mol. Genet. Metab. 77:127-135.

17. Kakkis, E., et al. 2004. Successful induction of immune tolerance to enzyme replacement therapy in canine mucopolysaccharidosis I. Proc. Natl. Acad. Sci.U. S. A. 101:829-834.

18. Shull, R.M., et al. 1994. Enzyme replacement in a canine model of Hurler syndrome. Proc. Natl. Acad. Sci. U. S. A. 91:12937-12941.

19. Kakkis, E.D., Matynia, A., Jonas, A.J., and Neufeld, E.F. 1994. Overexpression of the human lysosomal enzyme alpha-L-iduronidase in Chinese hamster ovary cells. Protein Expr. Purif. 5:225-232.

20. Sands, M.S., et al. 2001. Biodistribution, kinetics, and efficacy of highly phosphorylated and nonphosphorylated beta-glucuronidase in the murine model of mucopolysaccharidosis VII. J. Biol. Chem. 276:43160-43165.

21. Clarke, L., et al. 2008. Long-term efficacy and safety of laronidase in the treatment of mucopolysaccharidosis I. Pediatrics. In press.

22. Kakkis, E., et al. 2004. Intrathecal enzyme replacement therapy reduces lysosomal storage in the brain and meninges of the canine model of MPS I. Mol. Genet. Metab. 83:163-174.

23. Dickson, P., et al. 2007. Intrathecal enzyme replacement therapy: successful treatment of brain disease via the cerebrospinal fluid. Mol. Genet. Metab. 91:61-68. 